\title{
Vulnerabilidade da Palma Forrageira e pecuária bovina no Estado da Paraíba frente ao ataque da cochonilha do carmim
}

\author{
Vulnerability of the Palm forage and cattle ranching in the state of Paraíba against the \\ attack of carmine cochineal \\ AGUIAR ${ }^{1}$, S. C.; QUERINO² ${ }^{2}$ L. A. L.; $\operatorname{SILVA}^{3}$, P. F.; LIMA ${ }^{4}$, V. L. A. \\ saracameloag@hotmail.com
}

\begin{abstract}
Resumo
A palma tornou-se uma importante alternativa de forragem à pecuária bovina em meio às condições do semiárido, mas o ataque da cochonilha do carmim tem dificultado o cultivo da planta e a alimentação dos rebanhos. O presente estudo trata-se de uma revisão bibliográfica e tem como objetivo sistematizar e analisar os estudos referentes à situação de vulnerabilidade devido ao ataque da cochonilha do carmim no estado da Paraíba. Segundo as referências encontradas o ataque do inseto é caracterizado por prejuízos, a principal medida de controle tem sido o plantio de variedades de palma resistentes e o impacto sobre a pecuária bovina ainda é pouco abordado, demandando atenção dada à forte relação entre a atividade e os efeitos da praga. Por parte dos órgãos competentes as ações se dão de forma isolada e pontual, são insuficientes ao problema que deve ser encarado como demanda de política pública haja vista os severos impactos que a cochonilha do carmim causa à palma forrageira que repercutem nos rebanhos e nas famílias criadoras.
\end{abstract}

Palavras-Chave: Palma forrageira, pecuária bovina, vulnerabilidade.

\begin{abstract}
Palm has become an important forage alternative to cattle breeding under semi-arid conditions, but the attack of carmine cochineal has made it difficult to grow the plant and feed the herds. The present study is a bibliographical review and aims to systematize and analyze the studies referring to the situation of vulnerability due to the attack of the carmine cochineal in the state of Paraíba. According to the references found, the insect attack is characterized by losses, the main measure of control has been the planting of resistant palm varieties and the impact on cattle raising is still little approached, demanding attention given the strong relation between the activity and the effects of the pest. On the part of the competent bodies actions are taken in an isolated and punctual manner, they are insufficient to the problem that must be considered as a demand for public policy, given the severe impacts that the carmine cochineal causes on the forage palm that affect the herds and the creative families.
\end{abstract}

Keywords: Forage palm, cattle raising, vulnerability.

\section{INTRODUÇÃO}

Uma das dificuldades que o semiárido impõe à região de seu domínio é a produção de forragem dada à irregularidade pluviométrica característica do clima, dificuldade essa é amenizada graças à adaptação da cactácea exótica genericamente chamada de palma

${ }^{I}$ Sara Camêlo Aguiar, Programa de Pós-Graduação em Recursos Naturais, Universidade Federal de Campina Grande, Campina Grande-PB, Brasil.

${ }^{2}$ Luana Andrade Lima Querino, Programa de Pós-Graduação em Recursos Naturais, Universidade Federal de Campina Grande, Campina Grande-PB, Brasil.

${ }^{3}$ Patrícia Ferreira da Silva, Programa de Pós-Graduação em Recursos Naturais, Universidade Federal de Campina Grande, Campina Grande-PB, Brasil.

${ }^{4}$ Vera Lúcia Antunes de Lima, Departamento de Engenharia Agrícola, Universidade Federal de Campina Grande, Campina Grande-PB, Brasil. 
forrageira (Opuntia fícus-indica), que apresenta resistência ao pouco volume de água e às altas temperaturas do território semiárido.

A palma tornou-se a possibilidade mais contundente para a atividade da pecuária bovina no semiárido. A planta cuja cultura é perene ocupa importante papel na alimentação de rebanhos bovinos, sobretudo nos períodos extensos de estiagem representa sobrevivência para os animais e para as famílias criadoras que quase não possuem outras fontes de renda.

Mas a cerca de duas décadas, a presença e dispersão do inseto chamado de cochonilha do carmim (Dactylopius $s p$ ) tem dificultado essa alternativa para criação de bovinos na região afetada do semiárido.

Nesse sentido, o objetivo do presente artigo consiste sistematizar e analisar os estudos referentes à situação de vulnerabilidade devido ao ataque da cochonilha do carmim no estado da Paraíba.

\section{REVISÃO DE LITERATURA}

\subsection{Vulnerabilidade}

Vulnerabilidade é um termo interdisciplinar aplicável a diferentes campos temáticos, remetendo ao sentido de fragilidade, incialmente utilizado pela área da saúde expandiu-se para as mais variadas áreas para tratar das fragilidades naturais e sociais vivenciadas pelo homem em suas diferentes dimensões: individual, familiar e coletiva.

Segundo Wilches-Chaux (1998) vulnerabilidade é a condição em que uma população é ou está exposta ou mesmo susceptível de ser afetada por um fenômeno de origem humana ou natural, chamado de ameaça, semelhante ao conceito de Cardona (2012), que define como a propensão de elementos expostos, como seres humanos, seus meios de subsistência e bens para sofrer efeitos adversos.

A vulnerabilidade é uma característica de conotação negativa pertinente à relação homem-natureza, na qual o homem é frágil aos efeitos de suas próprias ações e aos advindos

de eventos naturais. É o grau de susceptibilidade de um sistema, o quanto esse não é capaz de lidar com efeitos adversos (ADGER, 2006). Assim como a relação da palma forrageira e pecuária bovina paraibana e seus componentes, a exemplo de produtores, rebanhos, palma forrageira com a cochonilha do carmim que tem agravado a vulnerabilidade da atividade nas condições semiáridas. 


\subsection{Pecuária bovina}

Se tratando especificamente da pecuária leiteira, no Brasil, as regiões Sul e Sudeste são as principais produtoras de leite do país, o Nordeste, em 2015, ocupava a quarta posição, à frente da região Norte, com uma produção anual de 4,2 milhões de litros de leite (IBGE, 2015).

Em 2015, o estado da Paraíba possuía um rebanho bovino de 1.170 .830 cabeças e obteve uma produção de 181,767 mil litros de leite (IBGE, 2015). O sistema de criação predominante no estado é o semiconfinado, com uma exploração familiar ou de subsistência, com uso de pouca tecnologia e baixa produtividade diária de leite. O volumoso mais presente na alimentação dos rebanhos é também o mais produzido no estado que é a palma forrageira (Opuntia fícus-indica). Dentre as raças bovinas mais adaptadas na Paraíba se destacam a Guzerá, Girolando e Sindi (CLEMENTINO et al., 2015).

\subsection{Palma forrageira (Opuntia fícus-indica)}

A palma forrageira (Opuntia fícus-indica), cujos primeiros registro se deram no Caribe e depois no México (KIESLING, 2013), contribui na garantia da sobrevivência para os rebanhos de ruminantes de muitas famílias da zona rural do semiárido.

Dentre as vantagens específicas da palma forrageira têm-se a perenidade da cultura, o alto valor nutricional e a rusticidade que despensa cuidados e representa mais resistência. Segundo Donato (2011) a palma apresenta baixos teores de matéria seca e grande volume de água com quantidade considerável de matéria mineral, além da maior eficiência no uso da água em função de seu Metabolismo Ácido das Crassuláceas (CAM).

No semiárido brasileiro está implantada a maior área cultivada com palma forrageira de todo o mundo, estima-se em 600 mil hectares (DUBEUX Jr et al., 2013). Conforme a adaptação da planta às condições semiáridas da região ela consegue resistir às altas temperaturas e ao regime irregular de chuvas e produzir grande quantidade de matéria verde por unidade de área.

\subsection{Cochonilha do carmim (Dactylopius sp) e palma forrageira (Opuntia fícus-indica)}

A cochonilha do carmim pertence à ordem Hemiptera, à família Dactylopiidae e ao gênero Dactylopius, possui 10 espécies dentre as quais existe a Dactylopius sp, originária do México, se encontra presente em diversos países (ADAPI, 2014). 
Em geral as diversas espécies da cochonilha do carmim atacam as culturas agrícolas sendo fortes pragas de fruteiras e plantas ornamentais. Especificamente a cochonilha do carmim da espécie Dactylopius sp é um inseto que se alimenta da seiva das plantas, podendo introduzir vírus e toxinas que degradam o tecido das plantas e matá-las (CARVALHO et al., 2007).

A cochonilha do carmim é facilmente identificada a partir da verificação da presença de flocos brancos, uma proteção de cera e de gordura que encobre os indivíduos chamada de colônias (Figura 1A), esses flocos quando esmagados liberam um líquido de cor vermelha (Figura 1B), o inseto suga a seiva da palma tornando-a amarela e murcha (Figura 1C).

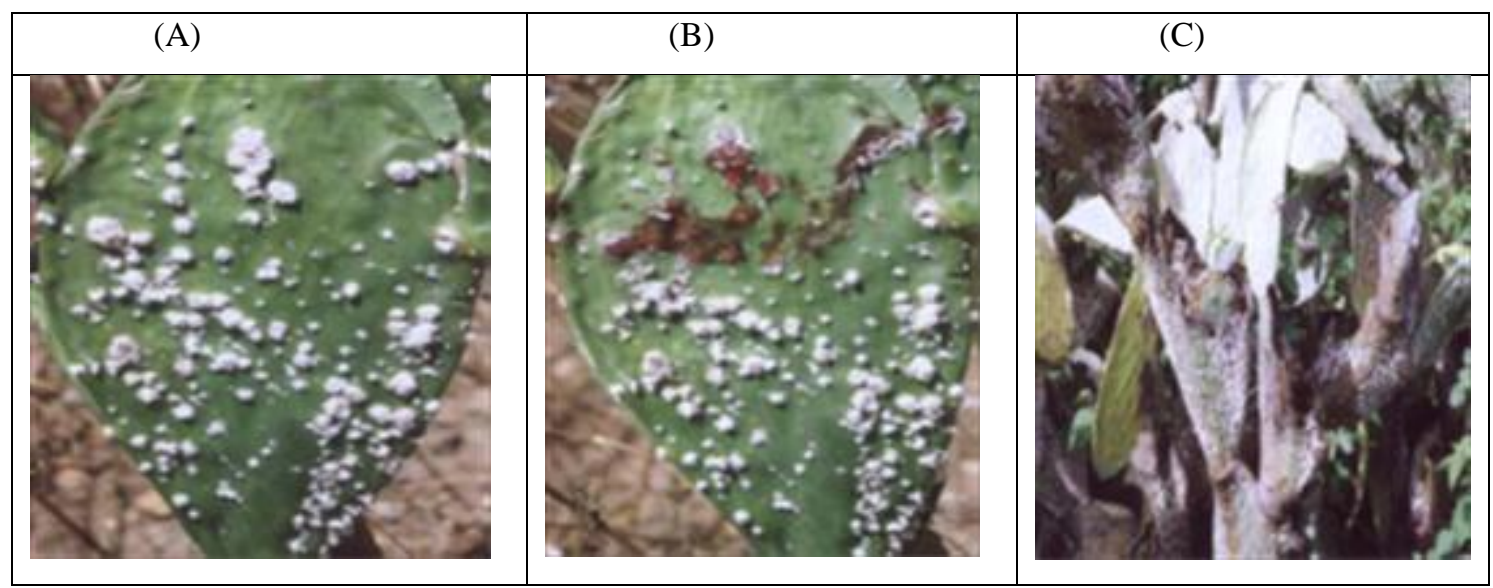

Figura 1: Colônias intactas (A), Colônias esmagadas (B) Palma forrageira "gigante" totalmente infestada pela cochonilha do carmim (C). Fonte: Carvalho et al., (2007).

Há registros a respeito da presença da cochonilha do carmim no Brasil em períodos anteriores (SIMÕES, 2005), contudo a entrada que consolidou sua presença no país, de acordo com Carvalho et al. (2007), se deu no município de Sertânia-PE, em 1998, o inseto foi trazido do México pelos pesquisadores do Instituto de Pesquisas Agronômicas do Estado de Pernambuco (IPA) para realização de pesquisas com o intuito de produzir corante como uma fonte extra de renda para os moradores da região.

Porém, desastrosamente os insetos se disseminaram a partir dessa área experimental para plantios de palma de propriedades vizinhas que logo foram infestados tornando-se novos focos de disseminação da praga, além disso, a dispersão da cochonilha também se deu pelo transporte da palma, comércio de animais infestados com os insetos, e até através do vento (SANTOS, 2009). 


\section{RESULTADOS E DISCUSSÃO}

\subsection{Ataque}

Após a detecção da cochonilha do carmim (Dactylopius sp) na cidade de Sertânia-PE, em 2001, foi constada a presença da praga nas cidades de Monteiro e Sumé no Cariri Ocidental da Paraíba e depois em municípios do Cariri Oriental paraibano.

Dentre as referências encontradas a mais antiga, Oliveira et al. (2008), realizaram um estudo para levantar a presença do inseto no período de 05 a 13 de janeiro de 2008, nos estados do Ceará, Pernambuco e Paraíba, entre os resultados alcançados têm-se que todos os pontos de coletas de amostras apresentaram a cochonilha do carmim, inclusive a Paraíba em todos os seus 16 pontos (OLIVEIRA et al., 2008).

Uma vez presente no hospedeiro o comportamento de uma praga se volta para sua infestação e dispersão, nesse sentido, Lopes et al. (2009a), objetivaram quantificar a velocidade de dispersão da cochonilha do carmim em condições de campo, como premissa para implementação de táticas de manejo integrado de pragas. $\mathrm{O}$ estudo foi realizado na Estação Experimental do município de Lagoa Seca-PB. O qual observou que a dispersão do inseto em palma gigante (Opuntia fícus-indica) no cladódio infestado artificialmente ocorre a partir de 8 dias e no máximo 20 dias, no espaçamento de 1,0 x 1,0 metro entre plantas e entre fileiras, respectivamente (LOPES et al., 2009a).

Ainda Lopes et al. (2009b), em outro estudo realizado no mesmo ano, avaliaram desta vez a velocidade de infestação e dispersão da cochonilha do carmim, também em condições de campo, visando estabelecer um nível de controle da praga, o estudo também foi realizado na Estação Experimental de Lagoa Seca-PB. Os resultados demonstram que com dez colônias/cladódio, o inseto tem um poder de infestação e dispersão altíssimo. Considerando 60 dias após da infestação foi observado o valor médio de até 171 colônias/planta. Fato que assegura que o nível de controle da cochonilha do carmim é menos de 10 colônias/planta e o combate deve ser iniciado logo após a detecção das primeiras colônias da praga no cultivo (LOPES et al., 2009b).

Avançando na dinâmica pertinente ao ataque da cochonilha do carmim há uma considerável literatura na identificação e discussão dos impactos causados pelo inseto. Almeida et al. (2011), registram uma queda na área plantada com palma na maioria dos municípios do Cariri Ocidental paraibano. Em Monteiro, o mais afetado, haviam as maiores áreas plantadas com palma na microrregião, cuja média de área de plantio era de 55,25ha por 
propriedade e após a infestação houve uma redução para 7,225ha por propriedade (ALMEIDA et al., 2011).

A perda da palma em função da cochonilha do carmim implica diretamente em prejuízo aos produtores, segundo Almeida et al. (2011), no Cariri Ocidental paraibano tem-se: a eliminação total ou parcial do palmal, diminuição do rebanho com perda de valor dos animais, compra de palma de outros produtores, prejuízo financeiro em cerca de $\mathrm{R} \$ 40.000$ mil reais e até mortalidade dos animais por falta de recurso forrageiro (ALMEIDA et al., 2011). Especificamente no município de Santo André a explosão populacional da cochonilha do carmim causou $100 \%$ de morte de todo palmal (SILVA et al., 2013).

As referências também abordam esses impactos sob o ponto de vista dos produtores, ainda com base no estudo de ALMEIDA et al. (2011) na microrregião do Cariri Ocidental, os mesmos afirmam que não há mais condições de plantar a palma, uns acabaram com o palmal, sendo que outros reduziram os rebanhos pela insuficiência de forragem (ALMEIDA et al., 2011). No município de Santo André, a maioria dos produtores, 90\%, afirmam que a cochonilha do carmim é a principal doença que acomete a palma (SILVA et al., 2013).

Conforme Leite (2009), já se tratando do Cariri Oriental paraibano, no município de Caturité, um dos mais afetados na microrregião, a praga chegou em seu território no ano de 2009, infestou 220ha dos 358ha de palma forrageira plantada e gerou um prejuízo de $\mathrm{R} \$$ 2.400,000 para o município. Conforme Macêdo (2014), nas comunidades rurais de Caturité, Malhada da Panela e Serraria, os produtores também relatam destruição dos palmais e consequente queda na produção, dificuldades para alimentar os bovinos e venda total ou parcial do rebanho em função da cochonilha do carmim.

Comparando os danos causados, Carmo, Júnior e Andrade (2016), classificam a cochonilha do carmim como uma praga potencialmente mais devastadora do que o bicudo do algodoeiro e o gafanhoto do Nordeste.

\subsection{Controle}

Se tratando do controle da cochonilha do carmim foram realizados estudos visando selecionar clones de palma forrageira resistentes à cochonilha do carmim, como fizeram Vasconcelos et al. (2009) constatando que entre 20 clones pesquisados os que apresentaram maior resistência ao ataque da praga foram a Doce ou Miúda (Nopalea cochenillifera) e a Orelha de Elefante (Opuntia spp), ao passo que o clone da Redonda (Opuntia ficus-indica) se mostrou altamente suscetível. A Doce ou Miúda foi considerada como imune, pois não 
permitiu o desenvolvimento do inseto e a Orelha de Elefante e a Algerian foram consideradas altamente resistentes, com nenhum ou poucos cladódios infestados. Todos os demais clones foram considerados suscetíveis a altamente suscetíveis (VASCONCELOS et al., 2009).

Em outro estudo genético foram utilizados 22 genótipos da planta (Opuntia spp e Nopalea spp) a partir da infestação de 20 colônias/cladódio, os resultados ratificam os anteriores. A palma Redonda, a Gigante (Opuntia ficus-indica) e várias outras variedades menos conhecidas são suscetíveis à cochonilha do carmim, enquanto que a palma Doce ou Miúda, Orelha de Elefante Africana e a Orelha de Elefante Mexicana são resistentes ao inseto (LOPES et al., 2010).

Tais comprovações científicas já estão presentes na realidade de alguns produtores, Almeida et al. (2011), afirmam que na microrregião Cariri Ocidental paraibano, a maioria dos produtores tem conhecimento sobre alguma variedade resistente à cochonilha do carmim, sendo a mais citada a palma Doce ou Miúda.

Porém, no município de Santo André, conforme Silva et al. (2013), ainda predomina o desconhecimento entre os produtores. Somente 5,55\% dos produtores responderam que conhecem variedades resistentes ao inseto, contudo não têm acesso as mesmas. Enquanto, $25 \%$ dos entrevistados afirmaram que não conheciam e apenas $20 \%$ responderam ter apenas ouvido falar (SILVA et al., 2013).

Nos municípios de Caturité e Boqueirão, no Cariri Oriental, segundo Pinto (2015), em termos quantitativos, as áreas revitalizadas são bem menores que as de cultivo tradicional e ainda estão em fase de testes, mas o suficiente para alguns produtores relatarem baixa produtividade, além da baixa resistência à seca e possuir muito espinho (PINTO, 2015).

Nesse sentido, o desconhecimento ainda significativo e a baixa aceitação das variedades resistente à cochonilha do carmim entre os produtores são desafios à difusão das mesmas. Para Macêdo (2014), esses entraves se devem a fatores como a falta ou insuficiência de assistência técnica aos produtores por parte dos órgãos competentes, e também à razões culturais em que a mudança é vista com descrença.

Outra ação de controle à cochonilha do carmim já estudada é a aplicação de produtos convencionais e alternativos para combater o inseto. Brito (2008) avaliou o comportamento de produtos alternativos comparo-os com produtos químicos recomendados no combate ao inseto. $\mathrm{O}$ estudo demostrou que tanto os produtos químicos, como os pesticidas parathiom metílico e dimethoato quantos os alternativos, como detergente neutro e sabão em pó, os óleos mineral e vegetal combateram eficazmente a cochonilha do carmim, com uma eficiência 
acima de $80 \%$. Porém, os produtos alternativos não mataram as larvas de Joaninhas e Baccha sp (Sirphidae). Enquanto que os pesticidas eliminaram larvas e adultos desses insetos (BRITO, 2008).

Carvalho et al. (2007), testaram a eficiência entre três tratamentos alternativos: biológico (fungos), natural (extratos de plantas), e domissanitários (sabões e detergentes). Os autores constataram que os referidos tratamentos embora tenham comprovada eficiência contra outras pragas agrícolas não são suficientes para controlar eficientemente a cochonilha do carmim na palma forrageira, uma vez que os produtos alternativos não atingem as cochonilhas que ficam protegidas por suas substâncias gordurosas e cerosas.

Porém, os autores salientam que o sabão em pó e o detergente não ocasionam nenhum efeito fitotóxico sobre a palma forrageira e se forem biodegradáveis têm a vantagem de não ocasionarem grandes impactos ambientais e de não oferecerem riscos a saúde dos aplicadores e animais (CARVALHO et al., 2007).

Quanto ao uso desses produtos, convencionais ou alternativos, por parte dos produtores para combater o ataque da cochonilha do carmim, segundo as referências estes têm utilizado mais os produtos alternativos. O estudo de Almeida et al. (2011), demonstra a utilização de controle alternativo por 16 produtores e do o controle químico por apenas 2 produtores. Em Silva et al. (2013), foi verificado que 99\% dos proprietários utilizam produtos caseiros como gás, óleo, sabão em pó e detergente neutro, somente $1 \%$ faz uso de inseticidas.

Seja o controle alternativo ou químico sua utilização aumenta os custos da produção, e por esse fato, a utilização de ambos ainda se mostra pequena entre os produtores (ALMEIDA et al., 2011).

Ainda como forma de contenção do avanço da cochonilha do carmim são citadas a importância da adoção de medidas preventivas como barreira sanitária e barreira fitossanitária (ALMEIDA et al., 2011), porém não há registro da adoção efetiva de nenhuma delas no estado da Paraíba.

Por parte dos órgãos públicos que dizem respeito ao enfretamento da cochonilha do carmim são citados a Empresa de Assistência Técnica e Extensão Rural (EMATER/PB) e as secretarias municipais com ações de assistência técnica, orientação e distribuição de espécies de palmas resistentes à praga, mas são apontadas como insuficientes (MACÊDO, 2014), (PINTO, 2015). O Instituto Nacional do Semiárido (INSA) é destacado pelo seu projeto Gabinete da Palma que objetiva a revitalização da cultura da palma forrageira através do 
plantio das variedades resistente à cochonilha do carmim, no qual pesquisadores e produtores se unem na multiplicação dessas espécies (MACÊDO, 2014).

\subsection{Pecuária}

A principal utilização da palma forrageira na região semiárida é a alimentação de rebanhos bovinos e a cochonilha do carmim representa indiretamente, porém de forma bastante contundente, uma grande dificuldade à pecuária. A palma forrageira é citada pela maioria dos produtores como a principal forragem dada aos rebanhos (SILVA et al., 2013).

Com o ataque da cochonilha do carmim, segundo Silva et al. (2013), foram ocasionadas sérias consequências para a pecuária bovina em Santo André-PB, no Cariri Ocidental, como perdas econômica para os proprietários rurais que tiveram que interromper o plantio da palma forrageira. Já nos municípios de Caturité e Boqueirão, no Cariri Oriental, a maioria dos produtores não tem como manter o rebanho e a renda suficientes para o sustento de suas propriedades rurais (PINTO, 2015). Nesse sentido, Almeida et al. (2011), vão além classificando a cochonilha do carmim como um elemento inviabilizador à pecuária na região.

O caminho apontado por Pinto (2015), para a garantia da permanência do homem no campo, bem como da bacia leiteira de Caturité que se destaca na microrregião do Cariri Oriental é a efetivação de políticas públicas de revitalização da palma forrageira resistente à cochonilha do carmim.

\section{CONCLUSÕES}

Há mais de duas décadas o estado da Paraíba vivencia a experiência ocasionada pela cochonilha do carmim (Dactylopius sp), assim como a partir das referências existentes acerca do tema foram abordados a presença, infestação, dispersão, impactos e que apontam para um aumento das dificuldades e, portanto, da vulnerabilidade da pecuária bovina na Paraíba.

Vale destacar que todos os desdobramentos ocorridos em função do ataque da cochonilha do carmim são perpassados por dois elementos que certamente são a base da vulnerabilidade a mais trazida pelo inseto, o desconhecimento dos produtores, que ainda estão aprendendo a lidar com o problema na prática sem conhecimento prévio, e a falta de assistência técnica por parte dos órgãos responsáveis que não cumprem seu dever nem mesmo em uma situação de grande dificuldade e desconhecimento pelos produtores. 
É fundamental que o combate e a convivência com a cochonilha do carmim sejam encarados como uma demanda de política pública, uma vez que o inseto representa uma ameaça à palma forrageira, aos rebanhos e às famílias criadoras desses rebanhos.

\section{REFERÊNCIAS}

ADAPI - Agência de Defesa Agropecuária do Piauí. Cochonilha do carmim, 2014. Disponível em: 〈http://www.adapi.pi.gov.br/palma-forrageira/cochonilha-do-carmim>. Acesso em Jun. 2014.

ADGER, W. N. Vulnerability. Global Environmental Change. v.16, n. 3, 2006. p. 268-281.

ALMEIDA, A. A. de; SILVA, R. A. da; ARAÚJO, W. L. de; OLIVEIRA, A. V. B. de; Leite, D. T. Problemas fitossanitários causados pela cochonilha do carmim a palma forrageira no Cariri Ocidental paraibano. Revista Verde, 6, 2011. p. 98-108.

BRITO, C. H. de; LOPES, E. B.; ALBUQUERQUE, I. C. de; BATISTA, J. de L. Avaliação de produtos alternativos e pesticidas no controle da cochonilha do carmim na Paraíba. Revista de Biologia e Ciências da Terra, 8, 2008. p. 1-5.

CARDONA, O. D.; AALST, M. V. Determinants of risk: exposure and vulnerability. In: Managing the Risks of Extreme Events and Disasters to Advance Climate Change Adaptation. Cambridge University Press, Cambridge, UK, and New York, NY, USA, 2012. p. 65-108.

CARMO JÚNIOR, E. L. do; ANDRADE, J. R. de. Os impactos negativos produzidos pela cochonilha do carmim (dactylopius sp.) na cultura da palma forrageira na região do semiárido.

Caderno de Estudos Avançados em Desenvolvimento Sustentável do Semiárido Ceades, 1, 2016. p. 38-48.

CARVAlHO, R. A.; LOPES, E. B.; SILVA, A. C.; LEANDRO, R. S.; CAMPOS, V. B. Controle alternativo da cochonilha do carmim em palma forrageira no cariri paraibano, $2007 . \quad$ Disponível em: 〈http://www.mma.gov.br/estruturas/174/_arquivos/174_05122008112054.pdf〉. Acesso em Jul. 2014.

CLEMENTINO, I. J.; PIMENTA, C. L. R. M.; FERNANDES, L. G.; BEZERRA, C. de S.; ALVES, C. J.; DIAS, R. A.; et al.. Caracterização da pecuária bovina no Estado da Paraíba, Nordeste do Brasil. Semina: Ciências Agrárias, 36, 2015, 557-570.

DONATO, P. E. R. Características morfológicas, de rendimento e nutricionais da palma forrageira sob diferentes espaçamentos e doses de esterco. Vitória da Conquista, Tese. (Doutorado em Zootecnia) - UESB, 2011.

DUBEUX JR, J. C.; SANTOS, M. V. F. dos; CAVAlCANTE, M.; SANTOS, D. C. dos. Potencial da palma forrageira na América do Sul. In: Nazareno, M. A.; Ochoa, M. 
J.; Dubeux Jr, J. C. (Eds.) Cactusnet Newletter. Universidad Nacional de Santiago del Estero, 2013. p. 29-40.

IBGE - Instituto Brasileiro de Geografia e Estatística. Produção da Pecuária Municipal 2015, 2015.2 Disponível em: 〈http://biblioteca.ibge.gov.br/visualizacao/periodicos/84/ppm_2015_v43_br.pdf $>$. Acesso em Maio 2017.

KIESLING, R. Historia and Prehistoria de la tuna o cactus, Opuntia ficus-indica: Presente y Futuro (History and prehistory of the cactus pear or cactus, Opuntia ficus-indica: Current and Future). In: Nazareno, M. A.; Ochoa, M. J.; Dubeux Jr, J. C. (Eds.) Cactusnet Newletter. Universidad Nacional de Santiago del Estero, 2013. p. 13-18.

LEITE, M. L. de M. V. Avaliação de clones de palma forrageira submetidos a adubações e sistematização de informações em propriedades do semiárido paraibano. Areia,Tese (Doutorado em Zootecnia) - UFPB, 2009.

LOPES, E. B.; ALBUQUERQUE, I. C. de; BRITO, C. H. de; BATISTA, J. de L. Velocidade de dispersão de Dactylopius opuntiae em Palma Gigante (Opuntia fícus- indica). Engenharia Ambienta, 6, 2009a. p. 644-649.

LOPES, E. B.; ALBUQUERQUE, I. C. de; BRITO, C. H. de; BATISTA, J. de L. Velocidade de infestação e dispersão de Dactylopius opuntiae Cockerell, 1896 em palma gigante na Paraíba. Engenharia Ambiental, 6, 2009b. p. 196-205.

LOPES, E. B.; BRITO, C. H. de; ALBUQUERQUE, I. C. de; BATISTA, J. de L. Seleção de genótipos de palma forrageira (Opuntia spp.) e (Nopalea spp.) resistentes à cochonilha-docarmim (Dactylopius opuntiae Cockerell, 1929) na Paraíba, Brasil. Engenharia Ambiental, 7, 2010. p. 204-215.

MACÊDO, H. C. de. Influência da cochonilha do carmim (Dactylopius opuntiae) sobre o sistema produtivo da palma forrageira (Opuntia fícus indica Mill) em Caturité-PB, 2014. Disponível em: 〈http://dspace.bc.uepb.edu.br:8080/xmlui/handle/123456789/4340>. Acesso em Nov. 2017.

OLIVEIRA, J. E. de M.; Pulz, C. E.; MIRANDA, J. dos R.; BARBOSA, F. R. Prospecção de Dactylopius (Hemiptera, Coccoidea) na Paraíba, Pernambuco e Ceará em Opuntia FicusIndica. In: Congresso Brasileiro de Entomologia. Uberlândia, 24 a 29 de ago. 2008.

PINTO, I. de O. Diagnóstico e revitalização da palma forrageira como alternativa da pecuária no cariri oriental da Paraíba. Campina Grande, Dissertação (Mestrado em Desenvolvimento Regional) - UEPB, 2015.

SANTOS, P. de S. Seleção de surfactantes e fotoprotetores para a formulação de Beauveria bassiana visando o controle de Dactylopius opuntiae em palma forrageira. Jaboticabal, Dissertação (Mestrado em Microbiologia Agropecuária) - UNESP, 2009. 
SILVA, C. D. da; SANTOS, N. M. R. da; Costa, P. V. da; Martins, M. T. C. S. Dactylopius opuntiae: Impactos causados e métodos alternativos utilizados em Opuntia ficus-indica no município de Santo André-PB. Scire, 2, 2013. p. 1-13.

SIMÕES, D. A.; SANTOS, D. C.; DIAS, F. M. Introdução da palma forrageira no Brasil. In: Menezes, R. S.C.; Simões, D. A.; Sampaio, E. V. S. B. (eds). A palma no Nordeste do Brasil conhecimento atual e novas perspectivas de uso. Recife: Editora UFPE, 2005. p. 1326.

VASCONCELOS, A. G. V. de; LIRA, M. de A.; CAVALCANTI, V. L. B.; SANTOS, M. V. F. dos; WILLADINO, L. Seleção de clones de palma forrageira resistentes à cochonilha-docarmim (Dactylopius sp). Revista Brasileira de Zootecnia, 38, 2009. p. 827-831.

WILCHES-CHAUX, G. Auge, caída y levantada de Felipe Pinillo, mecánico y soldador o yo voy a correr el riesgo guía de la red para la gestión local del riesgo. LARED Red de Estudios Sociales en Prevención de Desastres en América Latina. Peru, 1998.

Recebido em: 13/04/2019

Aceito para publicação em: 25/05/2019 